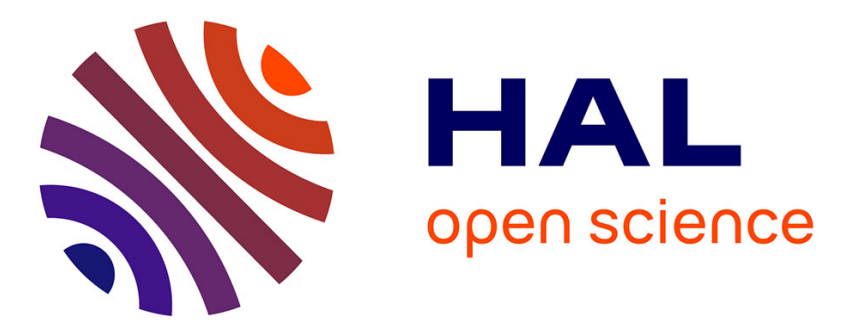

\title{
Multilevel Inverter Topology for Renewable Energy Grid Integration
}

\author{
Sid-Ali Amamra, Kamal Meghriche, Abderrezzak Cherifi, Bruno François
}

\section{To cite this version:}

Sid-Ali Amamra, Kamal Meghriche, Abderrezzak Cherifi, Bruno François. Multilevel Inverter Topology for Renewable Energy Grid Integration. IEEE Transactions on Industrial Electronics, 2017, 64 (11), pp.8855-8866. 10.1109/TIE.2016.2645887 . hal-01717607

\section{HAL Id: hal-01717607 https://hal.science/hal-01717607}

Submitted on 26 Feb 2018

HAL is a multi-disciplinary open access archive for the deposit and dissemination of scientific research documents, whether they are published or not. The documents may come from teaching and research institutions in France or abroad, or from public or private research centers.
L'archive ouverte pluridisciplinaire HAL, est destinée au dépôt et à la diffusion de documents scientifiques de niveau recherche, publiés ou non, émanant des établissements d'enseignement et de recherche français ou étrangers, des laboratoires publics ou privés. 


\title{
Multilevel Inverter Topology for Renewable Energy Grid Integration
}

\author{
Sid-Ali Amamra, Kamal Meghriche, Abderrezzak Cherifi, and Bruno Francois, Senior Member, IEEE.
}

\begin{abstract}
In this paper, a novel three-phase parallel grid connected multilevel inverter (MLI) topology with a novel switching strategy are proposed. This Inverter is intended to feed a microgrid from renewable energy sources (RES) to overcome the problem of the polluted sinusoidal output in classical inverters and to reduce component count, particularly for generating a multilevel waveform with a large number of levels. The proposed power converter consists of $n$ two-level $(n+1)$ phase inverters connected in parallel, where $n$ is the number of RES. The more the number RES, the more the number of voltage levels, the more faithful is the output sinusoidal wave form. In the proposed topology, both voltage pulse width and height are modulated and pre-calculated by using a pulse width and height modulation (PWHM) so as to reduce the number of switching states (i.e. switching losses) and the total harmonic distortion (THD). The topology is investigated through simulations and validated experimentally with a laboratory prototype. Compliance with the IEEE 519-1992 and IEC 61000-3-12 standards is presented and an exhaustive comparison of the proposed topology is made against the classical cascaded H-bridge topology.
\end{abstract}

Index Terms-Multilevel Inverter, conventional inverter topologies, Six level inverter, Pulse width and height modulation, THD optimization, power quality, grid integration, renewable energy sources.

\section{INTRODUCTION}

C URRENTLY, there are over $300 \mathrm{GW}$ of wind power generation and over $110 \mathrm{GW}$ photovoltaic generation installed worldwide. Renewable power plants of more than 10 MW in capacity become a reality [1]. However, the renewable energy sources have highly variable daily and seasonal patterns, and consumer power demand requirements are also extremely variable in nature [2]. Therefore, it is difficult to operate a stand-alone power system supplied from only one type of renewable energy source unless appropriate energy storage facilities. If enough energy storage capacity is not available, especially in medium to large-scale systems, a grid-connected renewable power generation may be the only practical solution [3].

For grid integration, the use of simple conventional inverter, two level, produces a square wave which is not suitable for most of the intricate applications. In such cases, a pure sinusoidal wave is desired. Even more, the traditional converters

Manuscript received July 29, 2016; revised October 28, 2016; accepted November 18, 2016.

Sid-Ali Amamra and Bruno Francois are with Univ. Lille, Centrale Lille, Arts et Metiers Paristech, HEI, EA 2697 - L2EP, Laboratoire d'Electrotechnique et d'Electronique de Puissance, F-59000 Lille, France (Email: sidali.amamra@yncrea.fr)

Kamal Meghriche and Abderrezzak Cherifi are with University of Versailles Saint-Quentin-en-Yvelines, Versailles Laboratory of Systems Engineering (LISV), Versailles, France rating power are limited to the rated power of the used semiconductor devices and the allowed switching frequencies [4]. Conventional inverters based on power-frequency transformers operating at 50 or $60 \mathrm{~Hz}$ and $\mathrm{AC}$ filters are generally used in renewable power generation systems to step up the voltage to the grid voltage levels of $6-36 \mathrm{kV}$ and to reduce the voltage THD respectively. High investment and installation costs are required because of its heavy weight and large size [5]. With the arrival of new high-power semiconductor devices, new power converter structures are designed to meet the needs of future medium or high-voltage converter systems. In this highly active area, the modular multilevel cascaded (MMC) converter topologies and circuits have attracted a high degree of attention for their application in medium and highvoltage systems [6], [7], [8]. The component numbers of MMC converters grow up linearly with the number of levels, individual modules are identical and modular in construction thereby enabling the attainability of a high level number [9]. However, the MMC converter requires balanced multipleisolated dc sources [10], [11]. Accordingly, its application is not straightforward, especially in renewable power generation systems.

From the Multilevel Inverter side, challenges are nowadays focused on increasing the inverter efficiency [12], [13], [14], improving the power quality and inverter efficiency by reducing THD, decreasing conduction and switching losses to name but a few [15], [16]. However, switching losses are higher than conduction losses and are proportional to the number of switching states [17], [18].

A good survey on multilevel dc-ac power converter topologies is given in [19], [20]. However, all these methods require a high switching frequency leading to increasing switching losses [21]. So, for practical implementation, the reduce of switching frequency is very essential also [22].

This work presents a novel three-phase parallel grid connected multilevel inverter topology with $\left(2 n^{2}-2\right)$ levels in the line output voltage waveform, to feed microgrid with $n$ renewable energy sources with an optimized THD. The proposed inverter consists of a parallel connection of $n$ twolevel $(n+1)$ phase inverters. Each stage of classic inverter is fed from a renewable energy source, for PV array through a DC-DC converter and for wind power through a AC-DC converter. A six level inverter application has been built in this work, the topology needs six legs $(2$ cascaded power switches per leg) fed by two renewable energy sources (i.e. wind energy and PV energy) and controlled by a pulse width and height modulation technique. It uses only 12 switching states per period and allows to eliminate from $2^{\text {nd }}$ up to 
$10^{t h}$ order harmonics without an extra filtering circuit. This approach reduce significantly the number of required power switches and the switching frequency as compared to the classical topologies. Moreover, the proposed topology shows similarities with the Cascaded H-bridge ( $\mathrm{CHB}$ ) topology in two ways: 1) It needs multiple isolated input dc voltages; and 2) input dc voltage levels can be combined into all additive values. The proposed topology and the related analysis along with simulation and experimental verification is the main contribution of this work.

The paper is organized as follows. Section II describes the generalized topology of the proposed multilevel inverter. In section III, a six level inverter application is studied and discussed, a selected harmonic elimination method is discussed. In section IV the simulation and experimental results along with their compliance to various international standards are validated. A comparison of the proposed topology with classical topologies is presented in Section V. Conclusions are summarized in section VI.

\section{Generalized Multilevel InVerter Topology AND OPERATING PRINCIPLE}

Fig.1 shows the generalized three-phase multilevel inverter topology. It consists of $n$ renewable sources ( $n$ DC sources) feeding microgrid. In general, the DC voltage sources can have different values. However, in order to optimize the total harmonic order of the multilevel output waveform, they are considered to be optimized, and regulated through DC-DC or AC-DC converters. The multilevel inverter consists of $2 n^{2}+2 n$ power switches, so $4 n^{2}+4 n$ insulated gate bipolar transistors (IGBT) with antiparallel diodes $S_{i, j}(1<i<2 n, 1<j<$ $(n+1))$. For instance, when $S_{11}$ and $S_{22}$ are turned ON, the output voltage $U_{a b}$ is equal to $E_{1}$, when $S_{11}, S_{24}, S_{34}, S_{43}$, $S_{53}$ and $S_{62}$ are turned $\mathrm{ON}$ the output voltages $U_{a b}, U_{b c}$ and $U_{c a}$ are $E_{1}+E_{2}+E_{3},-E_{3}$ and $-E_{2}-E_{1}$ respectively. $\mathrm{As} U_{a b}+U_{b c}+U_{c a}=0$ for each switching state, so a balanced system is obtained. Following the same combination, $n^{2}+2(n-1)$ possible levels $\left(E_{1}, E_{2},\left(E_{1}+E_{2}\right), E_{3}, \ldots . . E_{n}\right)$ for the output waveform are obtained. Therefore, the switches have to withstand both positive and negative voltages. In addition, the switches have to conduct backward current that is a result of the grid inductive nature. It can be concluded that the switches must be bidirectional. There are several circuit configurations for bidirectional switches In this study, the common emitter topology is used as it, requires only one gate driver per switch. Table I shows the states of the switches for each output voltage value, 1 corresponds to the switch ON state, 0 corresponds to the OFF state and $k$ is variable according to the switching state.

By considering Fig. 1, $2 n^{2}+2 n$ states are obtained, but some switching states are not allowed, to avoid a short circuits of renewable energy sources and/or output voltage, so:

$-S_{k j}$ and $S_{(k+1) j}(k=1,3,5, \ldots 2(n-1), j=1:(n+1))$ can not be $\mathrm{ON}$ in the same time to avoid a short circuit of renewable energy sources.

$-S_{i k}$ and $S_{i(k+1)}(i=1: 2 n$, and $k=1: 3)$ can not be $\mathrm{ON}$ in the same time to avoid short circuit of output voltages.
So, for each value of the output multilevel voltages, $2 n$ switches must be turned ON, two from each renewable energy source corresponding inverter.

By considering Fig. 1,

$$
\begin{gathered}
N_{\text {switch }}=\left\{\begin{array}{l}
6, \quad \text { for } n=1 \\
2 n^{2}+2 n \text { for } n \geq 2
\end{array}\right. \\
N_{\text {driver }}=N_{\text {switch }} \\
N_{\text {IGBT }}=2 N_{\text {switch }} \\
N_{\text {source }}=n
\end{gathered}
$$

where, $N_{\text {switch }}, N_{\text {driver }}, N_{I G B T}$, and $N_{\text {source }}$ are respectively the number of switches, number of switch drivers, number of IGBTs and number of renewable energy sources.

In addition, the number of levels synthesized by the topology is given by

$$
N_{\text {Level }}=N=2 n^{2}-2
$$

The peak voltage attained for such a configuration is given by

$$
v_{\max }=\sum_{1}^{n} E_{i}
$$

By considering $F_{S_{i j}}$ as connection function of switch $S_{i j}$, so

$$
F_{S_{i j}}= \begin{cases}0 & \text { if switch } S_{i j} \text { is turned OFF } \\ 1 & \text { if switch } S_{i j} \text { is turned ON }\end{cases}
$$

By using (7) and physical connection of the inverter, the electric potential at the output points $a, b$ and $c$ of the inverter with respect to the virtual neutral are deduced (see eq. 8).

The output phase-to-phase voltages can be obtained by using (8):

$$
\left\{\begin{array}{rl}
U_{a b} & =V_{a 0}-V_{b 0} \\
U_{b c} & =V_{b 0}-V_{c 0} \\
U_{c a} & =V_{c 0}-V_{a 0}
\end{array}=\left[\begin{array}{ccc}
1 & -1 & 0 \\
0 & 1 & -1 \\
-1 & 0 & 1
\end{array}\right]\left[\begin{array}{c}
V_{a 0} \\
V_{b 0} \\
V_{c 0}
\end{array}\right]\right.
$$

\section{A Six LeVEl INVERTER Application CONSIDERATIONS}

The six-level topology shown in Fig. 2 uses two renewable sources (as wind and solar emulators), which represented by two voltage sources $E_{1}$ and $E_{2}$ across the two capacitors $\left(C_{1}\right.$ and $\left.C_{2}\right)$. In this case $n=2$, from (1) this topology requires 12 switches $\left(S_{11}, S_{12}, S_{13}, S_{21}, S_{22}, S_{23}, S_{31}, S_{32}, S_{33}, S_{41}, S_{42}, S_{43}\right)$ and from (3) the topology will require 24 IGBTs.

From (8) the electric potential at the output points $a, b$ and $c$ of the inverter referred to a virtual neutral potential are deduced (10):

$$
\left\{\begin{array}{l}
V_{a 0}=\left(F_{S_{11}}-F_{S_{21}}\right) E_{1}+\left(F_{S_{31}}-F_{S_{41}}\right) E_{2} \\
V_{b 0}=\left(F_{S_{12}}-F_{S_{22}}\right) E_{1}+\left(F_{S_{32}}-F_{S_{42}}\right) E_{2} \\
V_{c 0}=\left(F_{S_{13}}-F_{S_{23}}\right) E_{1}+\left(F_{S_{33}}-F_{S_{43}}\right) E_{2}
\end{array}\right.
$$




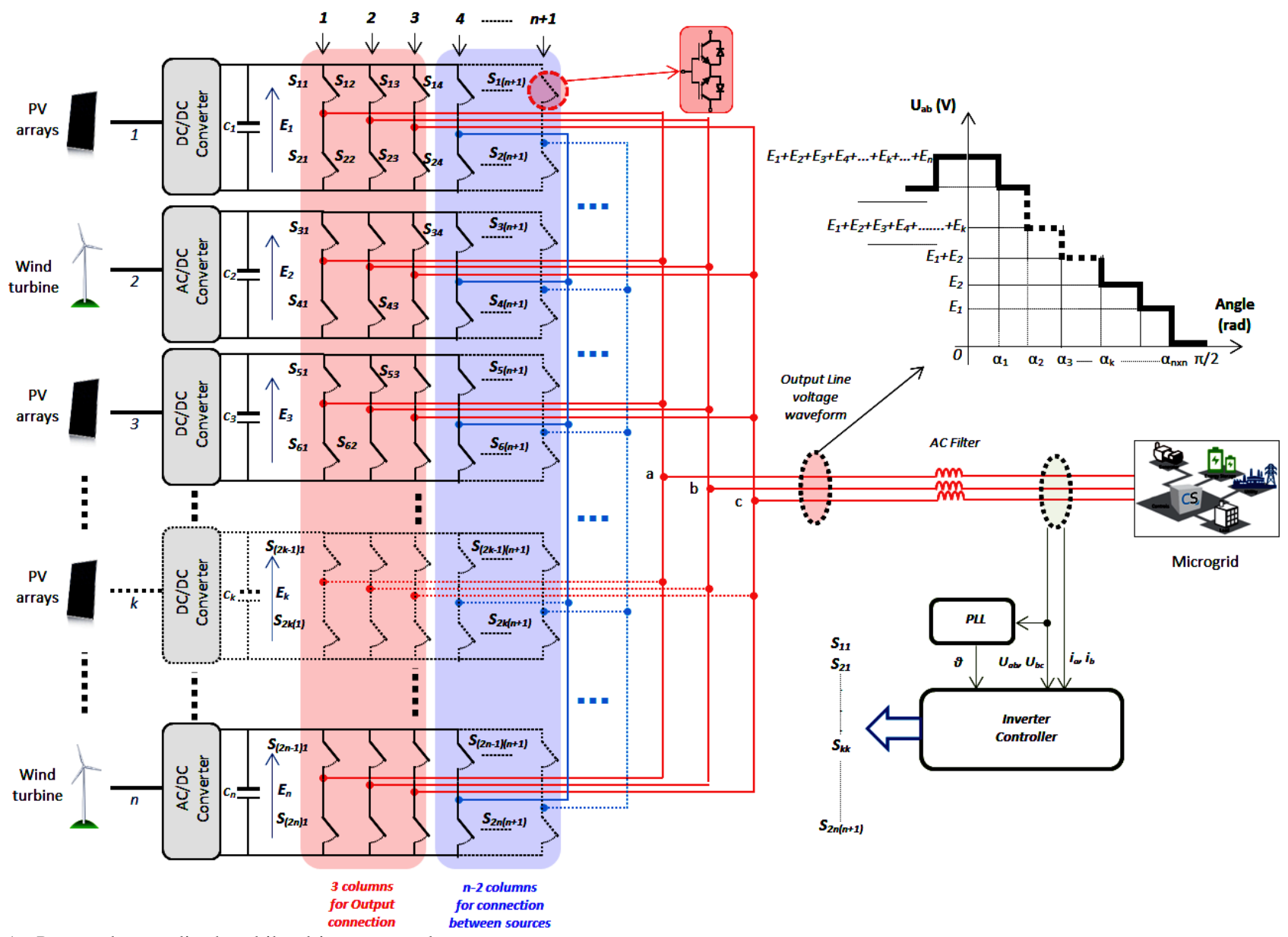

Fig. 1. Proposed generalized multilevel inverter topology

TABLE I

OUTPUT VOLTAGES FOR DIFFERENT STATES OF SWITCHES

\begin{tabular}{|c|c|c|c|c|c|c|c|c|c|c|c|c|c|c|c|c|c|c|c|c|c|c|}
\hline \multirow{2}{*}{ State } & \multicolumn{19}{|c|}{ Switches states } & \multirow{2}{*}{$U_{a b}$} & \multirow{2}{*}{$U_{b c}$} & \multirow{2}{*}{$U_{c a}$} \\
\hline & $S_{11}$ & $S_{12}$ & $S_{13}$ & $S_{14}$ & $\cdots$ & $S_{1(n+1)}$ & $S_{21}$ & $S_{22}$ & $S_{23}$ & $S_{24}$ & $\ldots$ & $S_{2(n+1)}$ & $\cdots$ & $S_{n 1}$ & $S_{n 2}$ & $S_{n 3}$ & $S_{n 4}$ & $\ldots$ & $S_{n(n+1)}$ & & & \\
\hline 1 & 1 & 0 & 0 & 0 & $\cdots$ & 0 & 0 & 0 & 0 & 1 & $\ldots$ & 0 & $\cdots$ & 0 & 1 & 0 & 0 & $\ldots$ & 0 & $\sum_{i=1}^{n} E_{i}$ & $-\sum_{i=1}^{k} E_{i}$ & $-\sum_{i=k}^{n} E_{i}$ \\
\hline 2 & 0 & 0 & 0 & 0 & $\cdots$ & 0 & 0 & 0 & 0 & 0 & $\ldots$ & 0 & $\cdots$ & 0 & 1 & 0 & 0 & $\cdots$ & 0 & $\sum_{i=1}^{n-1} E_{i}$ & $-\sum_{i=1}^{k+1} E_{i}$ & $-\sum_{i=n-1}^{k-1} E_{i}$ \\
\hline 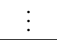 & & & & & & & & & & & & & & & & & & & & & & \\
\hline$N$ & 1 & 0 & 0 & 0 & $\cdots$ & 0 & 0 & 1 & 1 & 0 & $\ldots$ & 0 & . & 0 & 0 & 0 & 0 & & 0 & $E_{1}$ & $\sum_{i=2}^{n-k} E_{i}$ & $-\sum_{i=1}^{n-k} E_{i}$ \\
\hline
\end{tabular}

$$
\left\{\begin{array}{c}
V_{a 0}=\sum_{i=1}^{n}\left[\left(F_{S_{(2 i-1) 1}}-F_{S_{(2 i) 1}}\right) E_{i}+\sum_{j=4}^{n+1}\left(F_{S_{(2 i) j}}-F_{S_{(2 i-1) j}}\right)\left[\sum_{l=1,3,5 . .(l \neq i)}^{2 n-1}\left(F_{S_{l j}}-F_{S_{(l+1) j}}\right) E_{\frac{l+1}{2}}\right.\right. \\
V_{b 0}=\sum_{i=1}^{n}\left[\left(F_{S_{(2 i-1) 2}}-F_{S_{(2 i) 2}}\right) E_{i}+\sum_{j=4}^{n+1}\left(F_{S_{(2 i) j}}-F_{S_{(2 i-1) j}}\right)\left[\sum_{l=1,3,5 . .(l \neq i)}^{2 n-1}\left(F_{S_{l j}}-F_{S_{(l+1) j}}\right) E_{\frac{l+1}{2}}\right.\right. \\
V_{c 0}=\sum_{i=1}^{n}\left[\left(F_{S_{(2 i-1) 3}}-F_{S_{(2 i) 3}}\right) E_{i}+\sum_{j=4}^{n+1}\left(F_{S_{(2 i) j}}-F_{S_{(2 i-1) j}}\right)\left[\sum_{l=1,3,5 . .(l \neq i)}^{2 n-1}\left(F_{S_{l j}}-F_{S_{(l+1) j}}\right) E_{\frac{l+1}{2}}\right]\right]
\end{array}\right.
$$

As a result, the output phase-to-phase multilevel voltages will be given by (11).

$$
\begin{gathered}
\left\{\begin{array}{c}
U_{a b}=V_{a 0}-V_{b 0} \\
U_{b c}=V_{b 0}-V_{c 0}
\end{array}=\left[\begin{array}{ccc}
1 & -1 & 0 \\
0 & 1 & -1 \\
-1 & 0 & 1
\end{array}\right] .\right. \\
U_{c a}=V_{c 0}-V_{a 0} \\
{\left[\begin{array}{ll}
\left(F_{S_{11}}-F_{S_{21}}\right) & \left(F_{S_{31}}-F_{S_{41}}\right) \\
\left(F_{S_{12}}-F_{S_{22}}\right) & \left(F_{S_{32}}-F_{S_{42}}\right) \\
\left(F_{S_{13}}-F_{S_{23}}\right) & \left(F_{S_{33}}-F_{S_{43}}\right)
\end{array}\right]\left[\begin{array}{c}
E_{1} \\
E_{2}
\end{array}\right]}
\end{gathered}
$$

\section{A. Operation Principle}

The required six phase-to-phase voltage output levels $\left( \pm E_{1}, \pm E_{2} \pm\left(E=E_{1}+E_{2}\right)\right)$ are generated as follows:

1) When turning ON the switches $S_{13}, S_{22}, S_{31}$ and $S_{43}$ during the first cycle $\left[0, \alpha_{1}\right]$, three levels are generated for the three phase-to-phase voltages i.e, $U_{a b}=E_{1}+E_{2}, U_{b c}=-E_{1}$ and $U_{c a}=-E_{2}$. Fig.3 (left) shows the current path for this mode.

2) When turning ON the switches $S_{12}, S_{23}, S_{31}$ and $S_{42}$ during the second cycle $\left[\alpha_{1}, \alpha_{2}\right]$, three levels are generated 


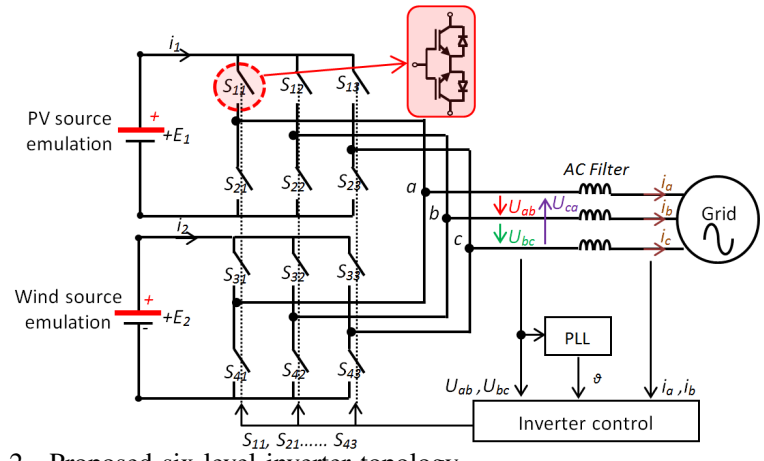

Fig. 2. Proposed six-level inverter topology

for the three phase-to-phase voltages i.e, $U_{a b}=E_{2}, U_{b c}=E_{1}$ and $U_{c a}=-E_{1}-E_{2}$. Fig.3 (right) shows the current path for this mode.
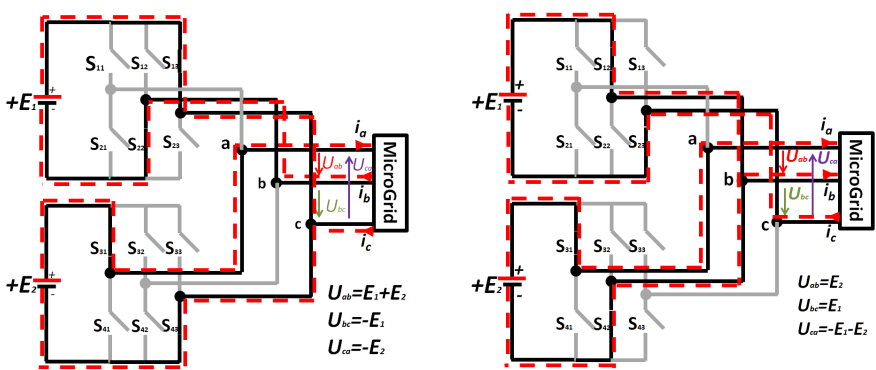

Fig. $\overline{3}$. Switching combination of the first cycle $\left[0, \alpha_{1}\right]$ (left) and the second cycle $\left[\alpha_{1}, \alpha_{2}\right]$ (right)

3) When turning ON the switches $S_{11}, S_{22}, S_{32}$ and $S_{43}$ during the third cycle $\left[\alpha_{2}, \alpha_{3}\right]$, three levels are generated for the three phase-to-phase voltages i.e, $U_{a b}=E_{1}, U_{b c}=E_{2}$ and $U_{c a}=-E_{1}-E_{2}$. Fig.4 (left) shows the current path for this mode.

4) When turning ON the switches $S_{12}, S_{21}, S_{31}$ and $S_{43}$ during the fourth cycle $\left[\alpha_{3}, \alpha_{4}\right]$, three levels are generated for the three phase-to-phase voltages i.e, $U_{a b}=-E_{1}, U_{b c}=$ $E_{1}+E_{2}$ and $U_{c a}=-E_{2}$. Fig.4 (right) shows the current path for this mode.
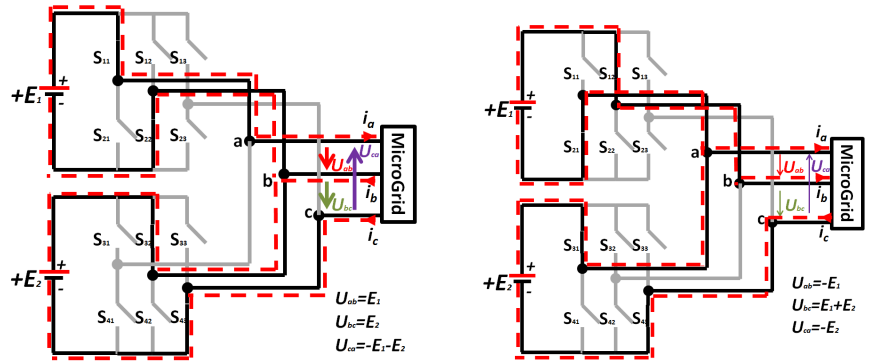

Fig. 4. Switching combination of the third cycle $\left[\bar{\alpha}_{2}, \bar{\alpha}_{3}\right]$ (left) and the fourth cycle $\left[\alpha_{3}, \alpha_{4}\right]$ (right)

5) When turning ON the switches $S_{12}, S_{23}, S_{32}$ and $S_{41}$ during the fifth cycle $\left[\alpha_{4}, \alpha_{5}\right]$, three levels are generated for the three phase-to-phase voltages i.e, $U_{a b}=-E_{2}, U_{b c}=E_{1}+E_{2}$ and $U_{c a}=-E_{1}$. Fig.5 (left) shows the current path for this mode.

6) When turning ON the switches $S_{13}, S_{21}, S_{32}$ and $S_{43}$ during the sixth cycle $\left[\alpha_{5}, \alpha_{6}\right]$, three levels are generated for the three phase-to-phase voltages i.e, $U_{a b}=-E_{1}-E_{2}, U_{b c}=$ $-E_{2}$ and $U_{c a}=E_{1}$. Fig.5 (right) shows the current path for this mode.
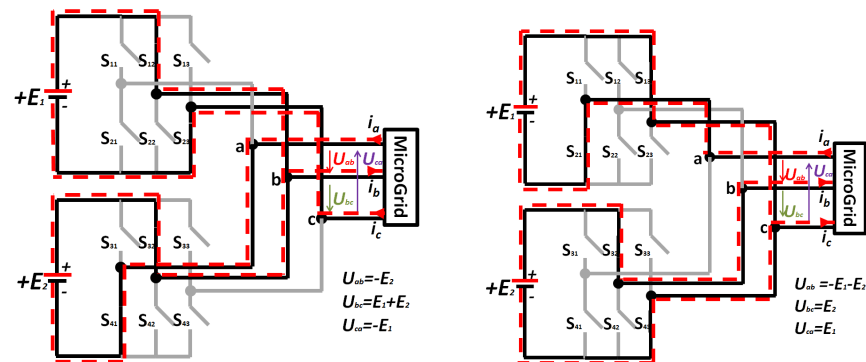

Fig. $\overline{\overline{5}}$. Switching combination of the fifth cycle $\left[\bar{\alpha}_{4}, \bar{\alpha}_{5}\right]$ (left) and the sixth cycle $\left[\alpha_{5}, \alpha_{6}\right]$ (right)

7) When turning ON the switches $S_{12}, S_{23}, S_{33}$ and $S_{41}$ during the seventh cycle $\left[\alpha_{6}, \alpha_{7}\right]$, three levels are generated for the three phase-to-phase voltages i.e, $U_{a b}=-E_{1}-E_{2}$, $U_{b c}=E_{1}$ and $U_{c a}=E_{2}$. Fig.6 (left) shows the current path for this mode.

8) When turning ON the switches $S_{13}, S_{22}, S_{32}$ and $S_{41}$ during the eighth cycle $\left[\alpha_{7}, \alpha_{8}\right]$, three levels are generated for the three phase-to-phase voltages i.e, $U_{a b}=-E_{2}, U_{b c}=-E_{1}$ and $U_{c a}=E_{1}+E_{2}$. Fig.6 (right) shows the current path for this mode.
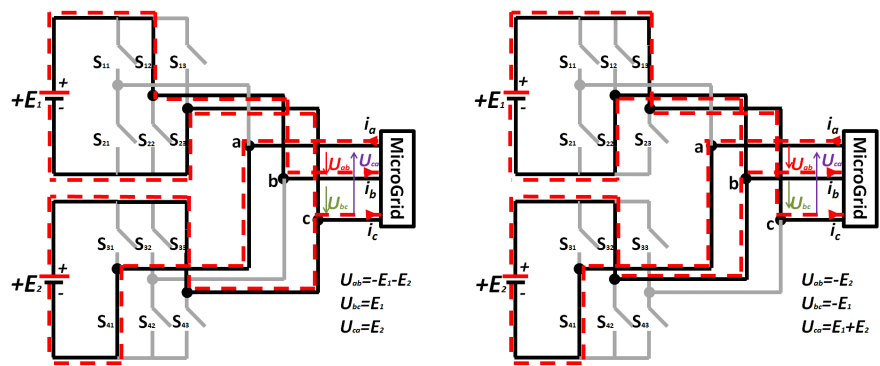

Fig. 6. Switching combination of the seventh cycle $\left[\alpha_{6}, \alpha_{7}\right]$ (left) and the eighth cycle $\left[\alpha_{7}, \alpha_{8}\right]$ (right)

9) When turning ON the switches $S_{12}, S_{21}, S_{33}$ and $S_{42}$ during the ninth cycle $\left[\alpha_{8}, \alpha_{9}\right]$, three levels are generated for the three phase-to-phase voltages i.e, $U_{a b}=-E_{1}, U_{b c}=-E_{2}$ and $U_{c a}=E_{1}+E_{2}$. Fig.7 (left) shows the current path for this mode.

10) When turning ON the switches $S_{11}, S_{22}, S_{33}$ and $S_{41}$ during the tenth cycle $\left[\alpha_{9}, \alpha_{10}\right]$, three levels are generated for the three phase-to-phase voltages i.e, $U_{a b}=E_{1}, U_{b c}=-E_{1}-$ $E_{2}$ and $U_{c a}=E_{2}$. Fig.7 (right) shows the current path for this mode.

11) When turning ON the switches $S_{13}, S_{21}, S_{31}$ and $S_{42}$ during the eleventh cycle $\left[\alpha_{10}, \alpha_{11}\right]$, three levels are generated for the three phase-to-phase voltages i.e, $U_{a b}=E_{2}, U_{b c}=$ $-E_{1}-E_{2}$ and $U_{c a}=E_{1}$. Fig.8 (left) shows the current path for this mode.

12) When turning ON the switches $S_{11}, S_{23}, S_{33}$ and $S_{42}$ during the twelfth cycle $\left[\alpha_{11}, \alpha_{12}\right]$, three levels are generated for the three phase-to-phase voltages i.e, $U_{a b}=E_{1}+E_{2}$, $U_{b c}=-E_{2}$ and $U_{c a}=-E_{1}$. Fig.8 (right) shows the current path for this mode. 

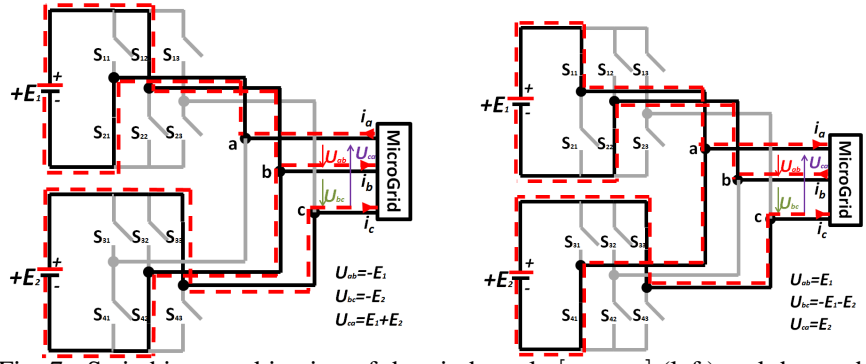

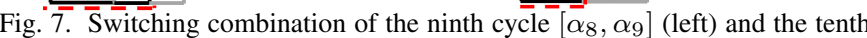
cycle $\left[\alpha_{9}, \alpha_{10}\right]$ (right)
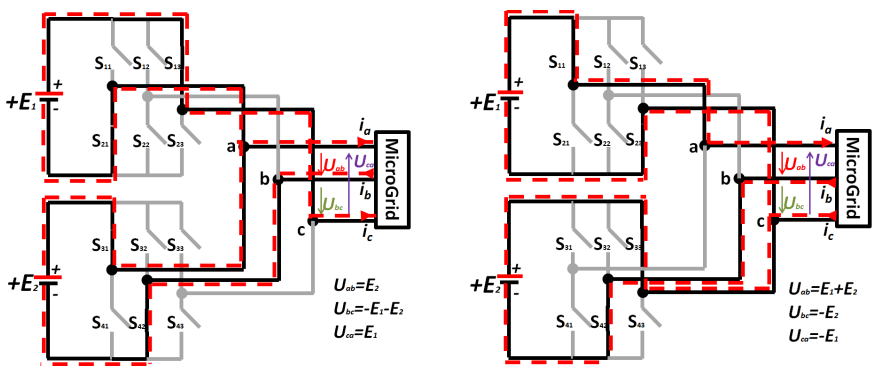

Fig. $\overline{8}$. Switching combination of the eleventh cycle $\left[\alpha_{10}, \alpha_{11}\right]$ (left) and the twelfth cycle $\left[\alpha_{11}, \alpha_{12}\right]$ (right)

The output waveform of the proposed six-level MLI can be seen in Fig. 9.

\section{B. Calculation of losses}

The losses associated with a power electronic converter can be equated with the aggregation of power losses incurred in the individual semiconductor devices. Losses incurred by a semiconductor device can be typically described under three categories: 1) when the device is blocking (i.e., OFF state); 2) when the device is conducting (i.e., ON state); and 3) when the device is switching (i.e., the state is changing from $\mathrm{ON}$ to $\mathrm{OFF}$ or vice versa). Since leakage currents during the blocking state are practically negligible [26], the losses are insignificant. Therefore, only conduction and switching losses are considered for the calculation of losses associated with the proposed inverter topology.

1) Conduction Losses: All switches required in the proposed topology are bidirectional conducting and bidirectional blocking, as shown in Fig. 1, the instantaneous conduction losses of typical transistor and diode are expressed as [28],

$$
\begin{aligned}
& \rho_{c, T}(t)=\left[V_{T}+R_{T} i^{\alpha}(t)\right] i(t) \\
& \rho_{c, D}(t)=\left[V_{D}+R_{D} i(t)\right] i(t)
\end{aligned}
$$

where $\rho_{c, T}(t)$ and $\rho_{c, D}(t)$ denote respectively the instantaneous conduction losses of the transistor device and diode. $V_{T}$ and $V_{D}$ are the ON-state voltage drops, while $R_{T}$ and $R_{D}$ are the equivalent $\mathrm{ON}$-state resistances of the transistor device and diode, respectively, and $\alpha$ is a constant governed by the transistor characteristics.

The conducting switches need to carry the output current $i_{a, b, c(t)}$ at a given instant of time. Both, transistor device and diode of a given switch conducts since all switches are bidirectional. Now, at any instant of time, let $N(t)$ be the number of conducting switches (i.e. diodes and transistor devices). Then, the average conduction losses can be expressed, by using equations (12) and (13), as

$$
\begin{aligned}
& \rho_{c, a v g}=\frac{1}{\pi} \int_{0}^{\pi}\left[\left\{N(t) V_{T}+N(t) V_{D}\right\} i_{a, b, c}(t)\right. \\
& \quad+\left\{N(t) R_{T} i_{a, b, c}^{\alpha+1}(t)\right\}+\left\{N(t) i_{a, b, c}^{2}(t)\right\} d(\omega t)
\end{aligned}
$$

2) Switching Losses: To calculate the total switching losses, a typical switch is first considered, and individual switching losses are then added to obtain the total switching losses of the inverter. To calculate the switching losses of an individual switch, a linear approximation of voltage and current during a switching period (transition from ON state to OFF state and vice versa) is used [28]. Energy losses during turn-on can be calculated as

$$
\begin{gathered}
E_{o n, j}=\int_{0}^{t_{o n}} v(t) i(t) d t \\
=\int_{0}^{t_{o n}}\left[\left\{V_{o, j} \frac{t}{t_{o n}}\right\}\right. \\
=\frac{1}{6} V_{o, j} I t_{o n}
\end{gathered}
$$

Where

$E_{\text {on }, j}$ turn-on loss of the $j^{\text {th }}$ switch;

$t_{\text {on }} \quad$ turn-on time;

I current through the switch after turning on;

$V_{o, j} \quad$ voltage that the $j^{t h}$ switch needs to block.

Similarly, energy losses of the $j^{t h}$ switch during turning off can be calculated as

$$
\begin{gathered}
E_{o f f, j}=\int_{0}^{t_{o f f}} v(t) i(t) d t \\
=\int_{0}^{t_{o f f}}\left[\left\{V_{o, j} \frac{t}{t_{o f f}}\right\}\right. \\
=\frac{1}{6} V_{o, j} I t_{o f f}
\end{gathered}
$$

where $t_{\text {off }}$ is the turn-off time for the $j^{\text {th }}$ switch and $I^{\prime}$ is the current through the switch before turning off. In $1 s$, the $j^{\text {th }}$ switch makes $f_{j}$ number of transitions, where $f_{j}$ is its switching frequency. Hence, by assuming that $I=I^{\prime}$, the total switching power losses can be calculated as

$$
\rho_{s}=\sum_{j=1}^{2 n^{2}+2 n}\left[\frac{1}{6} V_{o, j} I\left(t_{o n}+t_{o f f}\right) f_{j}\right]
$$

In Section $\mathrm{V}$, eq. (17) is used to demonstrate that the proposed topology incurs lower switching losses as compared to the classical CHB topology for a six-level PWM output. The total inverter losses can now be obtained by using (14) and (17) as

$$
\rho_{\text {losses }}=\rho_{c, a v g}+\rho_{s}
$$

\section{Optimized control parameters}

1) Fourier analysis: To optimize the THD of the output phase-to-phase voltage waveform, pulse weight and height modulation PWHM technique is used. Heights (magnitudes -" $E_{1}, E_{2}$ ") and widths (angles - " $\alpha_{1}, \alpha_{2}$ ") of the output waveform are calculated in order to cancel the maximum number of harmonics and optimize the THD (Fig.9). 


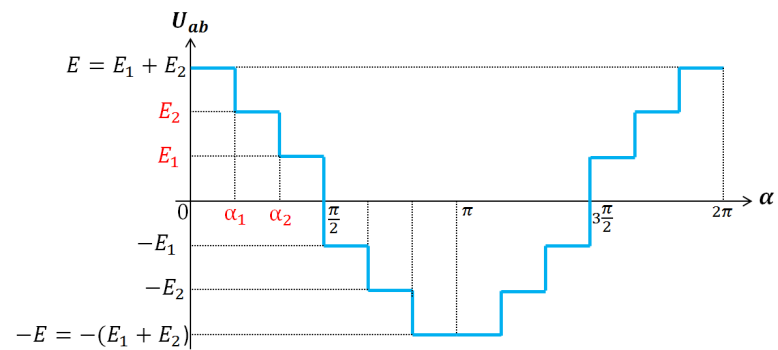

Fig. 9. Six-level output phase-to-phase voltage waveform

Equation 19 gives the Fourier coefficients of the phase-tophase voltage $U_{a b}$.

$$
\forall k \in N,\left\{\begin{array}{l}
a_{k}=\frac{2}{\pi} \int_{0}^{\pi} U_{a b} \cos (k \alpha) d \alpha \\
b_{k}=0
\end{array}\right.
$$

The three phase-to-phase voltages $\left(U_{a b}, U_{b c}, U_{c a}\right)$ are assumed to have the same symmetrical properties as an ideal three phase voltage system. Antisymmetric properties with respect to $\frac{\pi}{2}\left[u_{a b}\left(\frac{\pi}{2}+\alpha\right)=-u_{a b}\left(\frac{\pi}{2}-\alpha\right)\right]$ allows to cancel all even order harmonics. By using different symmetrical properties, $\alpha_{2}=\frac{\pi}{3}$ is obtained and the phase-to-phase voltage Fourier coefficients can be expressed in the interval $\left[0, \frac{\pi}{3}\right]$ as given by (20)

$$
a_{k=2 p+1}=\frac{8}{\pi} \cos \left(k \frac{\pi}{6}\right) \int_{0}^{\frac{\pi}{3}} U_{a b} \cos \left(k\left(\frac{\pi}{6}+\alpha\right)\right) d \alpha
$$

By using $k=3(2 p+1), \cos \left(k \frac{\pi}{6}\right)=\cos \left[(2 p+1) \cdot\left(\frac{\pi}{2}\right)\right]=0$ is obtained. This means that all even and multiple of three order harmonics are canceled.

The remaining non-canceled harmonics are of order $6 q \pm 1$. Eq.20 shows that setting the value of $U_{a b}$ is possible only within the interval $\left[0, \frac{\pi}{3}\right]$. The symmetry property of an ideal three-phase voltage system allows us to determine the value of $U_{a b}$ over the interval $[0,2 \pi]$. So, the next analysis will be limited within the interval $\left[0, \frac{\pi}{3}\right]$.

The phase-to-phase voltage $U_{a b}$ is assumed to have two DC levels $\left(E, E_{2}\right)$ within the interval $\left[0, \frac{\pi}{3}\right]$ as illustrated in Fig.10. $U_{a b}$ is assumed to have two pulses. The first pulse is of height (amplitude) $E$ and width (angle) $\alpha_{1}$. The second pulse is of height $E_{2}$ and width $\left(\frac{\pi}{3}-\alpha_{1}\right)$. Heights and widths are set to cancel the maximum number of successive harmonics.

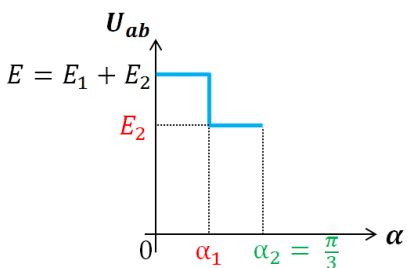

Fig. 10. Phase-to-phase voltage waveform $u_{a b}$ within $\left[0, \frac{\pi}{3}\right]$

By replacing the value of the phase-to-phase voltage $U_{a b}$ as seen in Fig.10 in (20), the Fourier coefficients in this case can be written as:

$$
\begin{aligned}
& \frac{a_{k=6 q \pm 1}}{E}=\frac{8}{k \pi} \cos \left(k \frac{\pi}{6}\right)\left\{(1-r) \sin \left[k\left(\frac{\pi}{6}+\alpha_{1}\right)\right]\right. \\
& \left.+r \sin \left[k\left(\frac{\pi}{6}+\frac{\pi}{3}\right)\right]-\sin \left(k \frac{\pi}{6}\right)\right\}
\end{aligned}
$$

Where, $r=\frac{E_{2}}{E}$ is the ratio of the two $D C$ voltage levels and $\alpha_{1}$ is the switching angle from $E$ to $E_{2} . \alpha_{1}$ and $r$ represents the two available adjustable variables. The selection of $\alpha_{1}$ and $r$ can be seen in next section i.e. in III-C2.

2) Harmonic elimination technique: Selected harmonics can be eliminated by a proper selection of adjustable variables $\alpha_{1}$ and $r$.

The system of nonlinear equations (see eq.21) can be mathematically solved only if the number of equations corresponds to the number of unknown variables. Since two adjustable variables are available, only two harmonics from (19) can be canceled. It is well known that low order harmonics are the most harmful than the higher order ones. The previous analysis shows that among low-order harmonics (less than $10^{\text {th }}$ ), only harmonics of $5^{t h}$ and $7^{t h}$ order are not canceled. They are eliminated only if the condition (22) is fulfilled.

$$
\left\{\begin{array}{l}
\frac{a_{5}}{E}=0 \\
\frac{a_{7}}{E}=0
\end{array}\right.
$$

In such case, the first non-zero harmonics is the $11^{\text {th }}$ order since $k \in\{1,11,13,17,19, \ldots, 6 q \pm 1\}$. By combining (21) and (22), a nonlinear system of two equations with two unknowns $\left(\alpha_{1}, r\right)$ is obtained.

$$
\left\{\begin{array}{l}
(1-r) \sin \left(5 \alpha_{1}-\frac{\pi}{6}\right)+r \sin \left(5 \frac{\pi}{3} \alpha_{1}-\frac{\pi}{6}\right)=-\frac{1}{2} \\
(1-r) \sin \left(7 \alpha_{1}-\frac{\pi}{6}\right)+r \sin \left(7 \frac{\pi}{3} \alpha_{1}-\frac{\pi}{6}\right)=+\frac{1}{2}
\end{array}\right.
$$

By solving (23), the values of $\alpha_{1}$ and $r$ are:

$$
\alpha_{1}=\frac{\pi}{6} \quad \text { and } \quad r=\sqrt{3}-1
$$

Accordingly,

$$
\left\{\begin{array}{l}
\frac{a_{1}}{E}=\frac{12}{\pi}(2-\sqrt{3})=1.0235 \\
a_{(k=12 p-1)}=-\frac{a_{1}}{k} \text { and } a_{(k=12 p+1)}=\frac{a_{1}}{k} \\
a_{k}=0 \text { if } k \neq 12 p \pm 1
\end{array}\right.
$$

So, the remaining non-zero harmonic orders are $\{11,13,23,25,35,37,47,49, \ldots, 12 p \pm 1\}$ as illustrated in Fig.11.

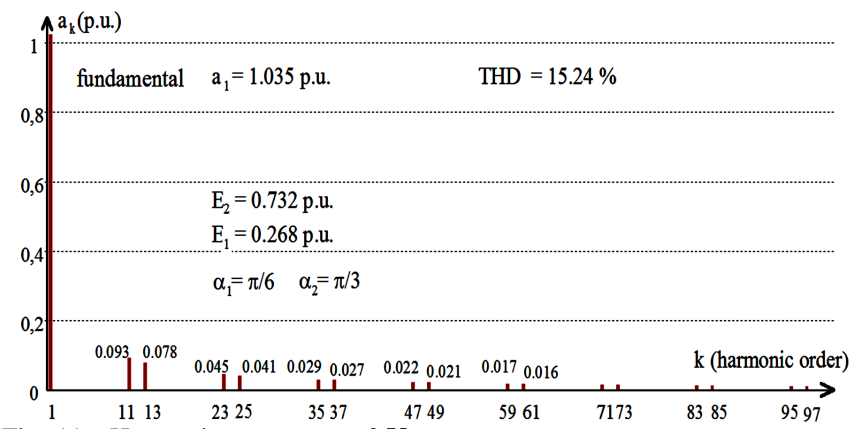

Fig. 11. Harmonics spectrum of $U_{a b}$

Again, by using symmetry properties of an ideal three-phase system, the output voltages are reconstructed within $\left[\frac{\pi}{3}, 2 \pi\right]$ [23]. Fig.12 shows the reconstructed output waveforms of the 
modulated output phase-to-phase voltages $U_{a b}, U_{b c}$ and $U_{c a}$. Consequently, a third voltage level $E_{1}$ appears in the interval $\left[\frac{\pi}{3}, \frac{\pi}{2}\right]$, with $E_{1}=E-E_{2}$, where

$$
\begin{aligned}
& E=1 p . u . \\
& E_{2}=r E_{1}=0.732 \text { p.u } \\
& E_{1}=E_{3}-E_{2}=1-0.732=0.268 \text { p.u. }
\end{aligned}
$$
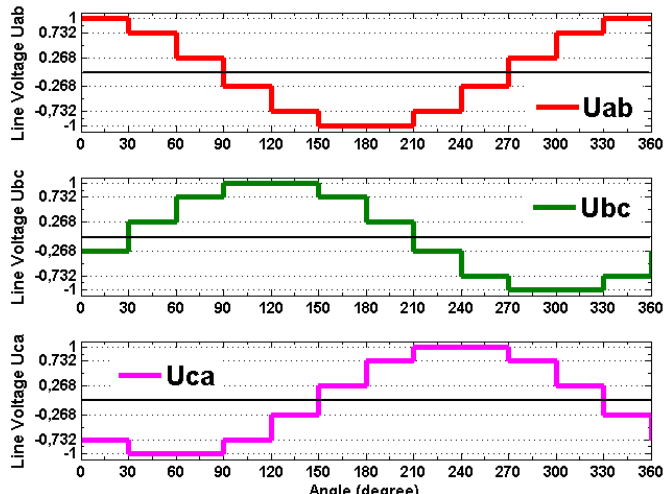

Fig. 12. Three phase six-level output phase-to-phase voltage waveforms

For laboratory practical considerations, two DC supplies are used with $E_{1}=0.268$ p.u. and $E_{2}=0.732$ p.u. The benefit of the proposed topology is that the first DC level can be obtained easily without extra cost since, $E=E_{1}+E_{2}=1$ p.u. In this case, the obtained fundamental magnitude will be $\frac{a_{1}}{E_{1}}=1.0235$ p.u.

\section{Simulation AND EXPERIMENTAL VALIDATIONS}

To examine the performance of the proposed MLI, simulations are carried out by using Matlab/Simulink and a prototype is implemented based on $A S P A C E \mathrm{P}-1103$ card (Fig.13). The circuit uses twelve bidirectional power switches $S_{11}, S_{12}, S_{13}, S_{21}, S_{22}, S_{23}$ fed by $E_{1}$ and $S_{31}, S_{32}, S_{33}, S_{41}$, $S_{42}, S_{43}$ fed by $E_{2}$. The power IGBT module from SEMIKRON: SKM145-GB123D, with built-in freewheeling diodes $(1200 \mathrm{~V}, 100 \mathrm{~A})$ is used. From (2), a twelve-gate driver board is built using opto-couplers $C N Y 17-4$. The $D C$ voltage inputs of the topology were provided by laboratory regulated $D C$ voltage supplies to emulate renewable energy sources (Wind or Solar).
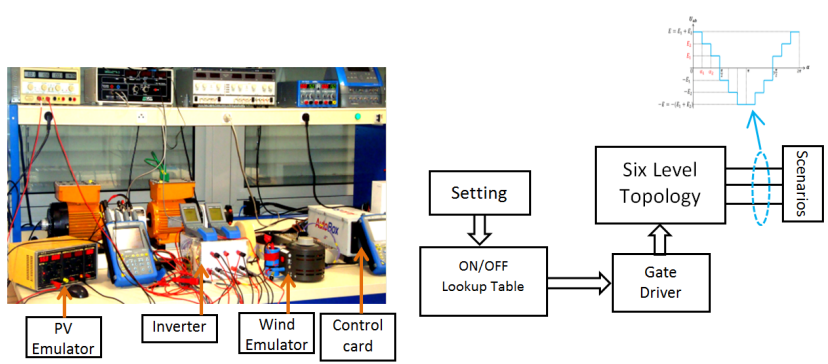

Fig. 13. Experimental setup and control block diagram

\section{A. Simulation results}

The r.m.s value can be calculated from within 0 to $\frac{T}{4}$, where $T$ is the period of the signal (25).

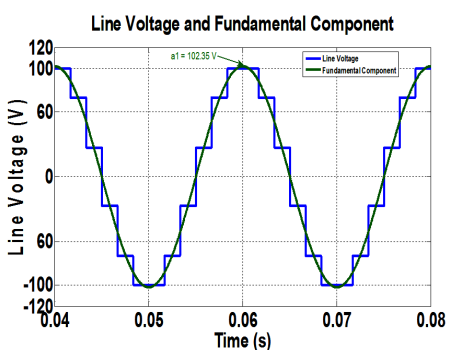

Fig. 14. Inverter phase-to-phase output voltage and its fundamental

$$
U=\sqrt{\frac{4}{T} \int_{0}^{\frac{T}{4}} u_{a b}^{2} d t} \Rightarrow U=\sqrt{\frac{4}{T} \frac{T}{12}\left(E_{1}^{2}+E_{2}^{2}+E^{2}\right)}
$$

In this case, $E_{1}=26.8 \mathrm{~V}$ and $E_{2}=73.2 \mathrm{~V}$ so $E=E_{1}+E_{2}=100 \mathrm{~V}$ and $U=100 \sqrt{\frac{1}{3}\left(1+0.732^{2}+0.268^{2}\right)}=73.2 \mathrm{~V}$

The output phase-to-phase voltage where $\alpha_{1}=\frac{\pi}{6} \quad r=\sqrt{3}-1$ can be seen in Fig.14. The voltage across the power switch can be seen in Fig. 15. To better evaluate the performance of the proposed topology, three simulation scenarios are considered. The different parameters are: $E_{1}=26.8 \mathrm{~V}, E_{2}=73.2 \mathrm{~V}$ and $E=E_{2}+E_{1}=100 \mathrm{~V}$. The scenarios consist of feeding a star connected resistive, inductive and grid connected loads.

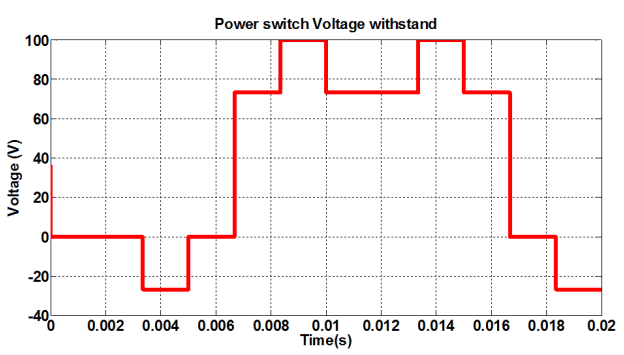

Fig. 15. The voltage across the power switch

1) Scenario 1. Pure resistive star connected load $R=45 \Omega$. $\therefore$ In this scenario, star connected power resistor is considered $R=45 \Omega$. Fig. 16 shows that the line current has the same form as the phase-to-phase voltage because of the load resistive nature. The value of the current THD is $15.24 \%$ where the fundamental magnitude is $0.928 \mathrm{~A}$.
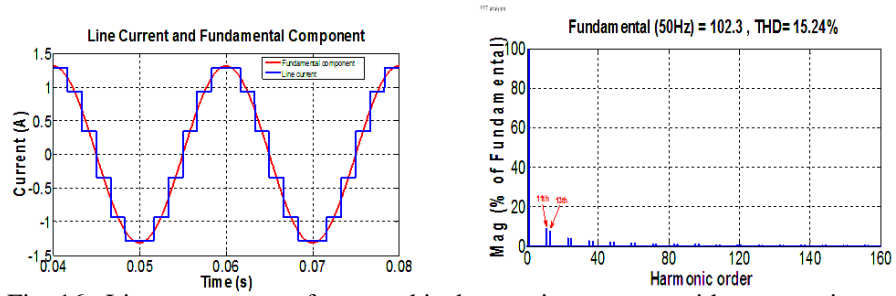

Fig. 16. Line current waveforms and its harmonic spectrum with a star resistor load

2) Scenario 2. Pure inductive star connected load $L=$ $245 \mathrm{mH}$ : In this case, a star connected pure inductive load is considered. Fig.17 shows that the current waveform has almost no harmonics. Also the value of THD in this case is very low i.e. $1.05 \%$ and the first non-zero harmonic order is the $11^{\text {th }}$ with a magnitude of $0.0044 \%$. The main reason of having very low THD is the inductive load behaving as a low pass filter. 

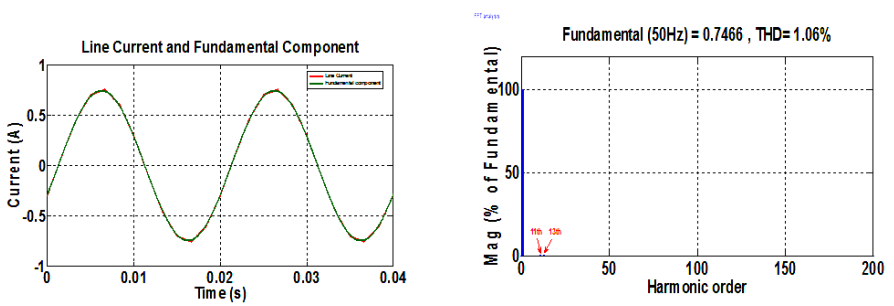

Fig. 17. Line current waveform and harmonic spectrum with an inductive load
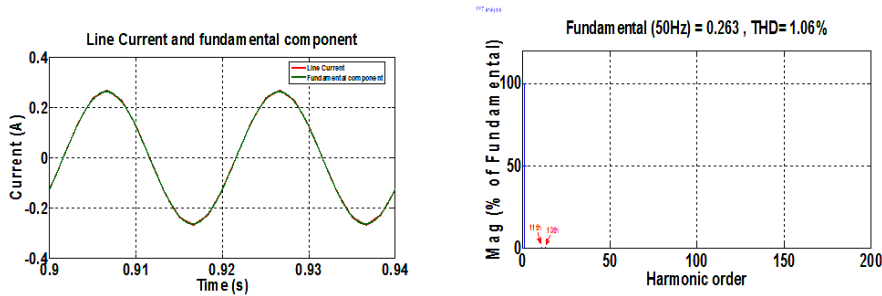

Fig. 18. Line current waveform and harmonic spectrum for grid connection

\section{3) Scenario 3. Inverter connected to the grid}

: Fig.18 shows the current waveform and harmonic spectrum for scenario 3. In this case, the inverter was connected to the grid. The THD is very low. The results show the capability of the proposed inverter to generate the desired output voltage waveform, the optimized output staircase phaseto-phase voltage is depicted Fig.9, and line current waveforms in Figures 10,11and 12 for resistive load, inductive load and grid connected scenarios respectively. Simulation results demonstrate the effectiveness of the proposed harmonic elimination technique (i.e. selection of $\alpha_{1}$ and $r$ ). Figures 16, 17 and 18 show also the first 100 harmonics (FFT) of line currents for the three different scenarios. The phase-to-phase voltage FFT analysis shows that $5^{\text {th }}$ and $7^{\text {th }}$ harmonics have been eliminated. The first non zero harmonic is of order 11.

\section{B. Experimental verification}

The first two simulation scenarios have been verified experimentally while we were not able to experiment the third scenario (i.e. grid connection) because of the non-availability of adequate equipment in the laboratory. Fig. 19 shows the control pulse signal for switches $\left(S_{11}, S_{12}, S_{13}, S_{21}, S_{22}, S_{23}\right)$ and $\left(S_{31}, S_{32}, S_{33}, S_{41}, S_{42}, S_{43}\right)$. Each switch has only 4 commutations per fundamental cycle, thus reducing power losses.
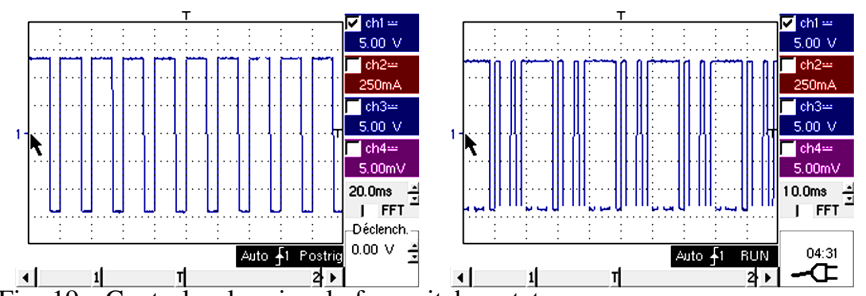

Fig. 19. Control pulse signals for switches states

Each power switch commutes with a frequency equal to $F_{\text {semiconductor }}=4 . F_{\text {fundamental }}$, thus switching losses are reduced in comparison with conventional PWM methods.
1) Scenario 1. Pure resistive star connected load $R=45 \Omega$ : Fig.20 shows the output voltage and current waveform and harmonics spectrum feeding a resistive star connected load . The output voltage is $200 V_{P P}$ and the output current is $2.7 A_{P P}$, the frequency is $50 \mathrm{~Hz}$.
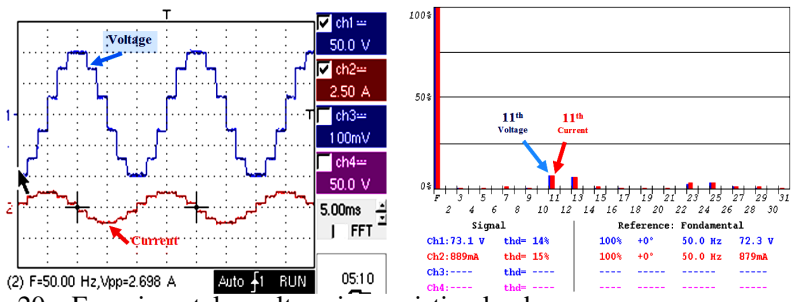

Fig. 20. Experimental results using resistive load

It shows a match between the simulation and experimental results. In fact, both voltage and current harmonic spectra show that the first nonzero harmonic is of $11^{\text {th }}$ order, followed by harmonics of $13^{t h}, 23^{\text {th }}$ and the $25^{\text {th }}$ orders.

2) Scenario 2. Pure inductive star connected load $L=$ $245 \mathrm{mH}$

: In the case of inductive load. Fig. 21 illustrates the experimental voltage and current waveforms and harmonic spectrum. The output phase-to-phase voltage is $72.5 \mathrm{~V}$ and the output current is $538 \mathrm{~mA}$. The inductive load cancels the output current harmonic. It behaves as a low pass filter, generating a sinusoidal line current.
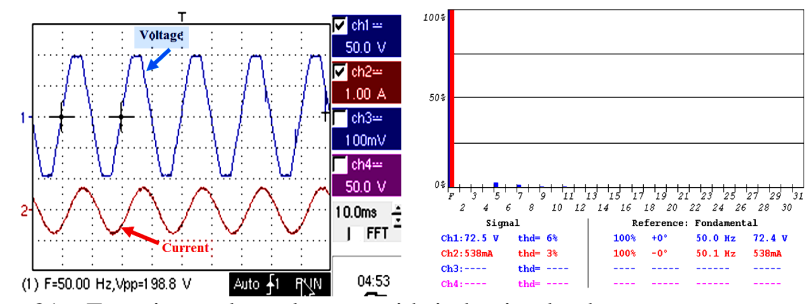

Fig. 21. Experimental results test with inductive load

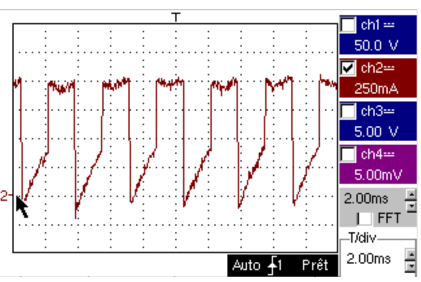

Fig. 22. DC bus current

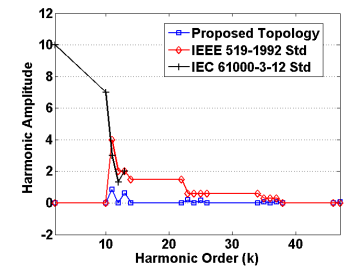

Fig. 23. Inverter waveform compliance with IEEE and IEC standard
Fig.22 shown the evolution of the current over the DC bus.

Fig.20 and Fig.21 show the measured output phase-tophase voltages, line currents and their frequency spectrum. The output phase-to-phase voltage frequency for all scenarios was $50 \mathrm{~Hz}$ with maximal magnitudes equal to $E_{1}+E_{2}=100 \mathrm{~V}$. The first non-zero harmonic is of $11^{\text {th }}$ order. The output current exhibits a sinusoidal-shape since the load behaves as an $R L$ low pass filter. The output currents contain less high-order harmonics than the output voltages. 
TABLE II

COMPONENT REQUIREMENTS AND TOTAL VOLTAGE STRESSES FOR THREE-PHASE MLIS (N IS THE NUMBER OF LEVELS IN PHASE VOLTAGE)

\begin{tabular}{|l|c|c|c|c|}
\hline Inverter type / component & NPC & Flying capacitor & Cascaded H-Bridge & Proposed Topology \\
\hline \hline Number of main switches & $6(N-1)$ & $6(N-1)$ & $6(N-1)$ & $2 N+2 \sqrt{2 N+4}+4$ \\
\hline Number of main diodes & $6(N-1)$ & $6(N-1)$ & $6(N-1)$ & $2 N+2 \sqrt{2 N+4}+4$ \\
\hline Number of clamping diodes & $3(N-1)(N-2)$ & 0 & 0 & 0 \\
\hline Number of DC bus capacitors / Isolated supplies & $(N-1)$ & $(N-1)$ & $3(N-1) / 2$ & $\frac{1}{2} \sqrt{2 N+4}$ \\
\hline Number of flying capacitors & 0 & $(3 / 2)(N-1)(N-2)$ & 0 & 0 \\
\hline Total component count & $(N-1)(3 N+7)$ & $(1 / 2)(N-1)(3 N+20)$ & $27(N-1) / 2$ & $4 N+\frac{9}{2} \sqrt{2 N+4}+8$ \\
\hline
\end{tabular}

\section{Compliance with IEEE 519-1992 and IEC 61000-3-12 standards}

The IEEE 519-1992 and IEC 61000-3-12 standards provide limits for the harmonic currents produced by electrical equipment's [24], [25]. For inductive loads (electric machines, passive filters, transformers), which represent $80 \%$ of the power converter applications, the output current harmonic magnitudes are $a_{k(\text { current })}=\frac{a_{k(\text { voltage })}}{k}$, where $k$ is the harmonic order .

Fig. 23 shows clearly the compliance of the proposed sixlevel inverter output signal with internationally recognized standards. The first nonzero harmonic is the $11^{\text {th }}$ order, meaning that the most harmful harmonics of $5^{t h}$ and $7^{\text {th }}$ orders are canceled along with all even-order harmonics.

\section{COMPARISON WITH OTHER TOPOLOGIES}

In this section, comparison of the proposed topology is made with other topologies. In Section V-A, the topology is compared with classical topologies in terms of component requirements. In Section V-B, an exclusive and exhaustive comparison is carried out with the CHB topology because, as mentioned earlier, the proposed topology resembles the CHB in configurational and functional features.

\section{A. Overall Comparison With Classical Topologies}

The component requirements of various topologies for a three-phase configuration are given in Table-II in terms of the number of voltage levels $(N)$ in the phase-to-phase voltage. It can be inferred from the table that the number of components in the proposed structure is lower than those in other topologies, particularly for higher number of voltage levels. For example, implementing a thirty-level inverter will entail component counts of 2813, 1595, and 391 for the NPC, FC, and $\mathrm{CHB}$ topologies, respectively, but only 164 in the proposed topology.

\section{B. Comparative Analysis of the Proposed Topology With the CHB Topology}

In this section, a comparison between the proposed inverter and CHB inverter is carried out in terms of voltage level and power component requirements and switching losses. For the purpose of comparison, both topologies are configured such that both have equal number of dc sources as input. Thus, with " $n$ " number of sources, each equal to $V_{d c}$ for CHB topology and $E_{1}$ and $E_{2}$ for the proposed topology (see Fig.2), the number of levels is given by (5) for the proposed topology and
$2 n+1$ for CHB topology [26], [27], and the maximum output voltage attained is given by (6) for the proposed topology and $n V_{d c}$ for CHB topology [28].

Voltage levels and power switch Requirements: With " $n$ " number of dc sources, the CHB topology provides " $2 n+1$ " voltage levels, while the proposed topology provides " $2 n^{2}-$ 2 " voltage levels. The difference in the numbers of voltage levels is significantly large. For example, for a three-phase 30level voltage, a CHB inverter requires $14 \mathrm{dc}$ sources and 174 power switches, whereas the proposed topology needs only 4 dc sources and 80 power switches.

Switching Losses: With an appropriate switching control, the proposed topology can be implemented with lower switching losses as compared to the CHB topology. For a five-level inverter with two equal input dc sources of voltage $V_{d c}$ for the CHB topology and the six level inverter with dc sources of voltage $E_{1}$ and $E_{2}$ for the proposed topology (see Fig.2), such as $E_{1}+E_{2}=2 . V_{d c}$, the average switching power loss $\rho_{s}$ in the switch caused by switching transitions can be defined by using (17) as

$$
\rho_{s}=\frac{1}{6} V_{0} I_{0}\left(t_{o n}+t_{o f f}\right) \cdot f
$$

where $t_{o n}$ and $t_{o f f}$ are the turn-on and turn-off crossover intervals, respectively, $V_{o}$ is the voltage blocked by the switch, $I_{o}$ is the switch current, and $f$ is the switching frequency. For simplification, it is assumed that switches operate with the same $t_{o n}$ and $t_{\text {off }}$ values while they carry the same current $I_{o}$. Thus, $\rho s$ can be approximated as

$$
\rho_{s}=\zeta V_{0} f
$$

where $\zeta\left[=\frac{1}{6} I_{o}\left(t_{o n}+t_{o f f}\right)\right]$ is a constant. Thus, switching power losses in the CHB five-level inverter in which all twenty-four switches operate at a high switching frequency ( $f_{s} \geqq 21 . f_{0}$, based on carrier signals, $f_{0}$ is the fundamental frequency) while blocking the same voltage $V_{d c}$ can be averaged as

$$
\rho_{s, C H B / 5 L}=24 \zeta V_{d c} f_{s}=504 \zeta V_{d c} f_{0}
$$

Similarly, the switching power losses of the proposed sixlevel inverter with twenty-four switches operating at low switching frequency $\left(f_{s}=4 . f_{0}\right.$, since each switch commutes fourth's time per period in six level topology as depicted in section-III-A while blocking the dc voltage $E_{1}$ and $E_{2}$ corresponding for each switch can be obtained as 


$$
\rho_{s, \text { proposed } / 6 L}=12 \zeta E_{1} f_{s}+12 \zeta E_{2} f_{s}=192 \zeta V_{d c} f_{0}
$$

While $E_{1}+E_{2}=2 . V_{d c}$.

It is clear from (28) and (29) that, the switching losses incurred in the proposed topology are almost half the switching losses incurred in the CHB topology.

\section{CONCLUSION}

The proposed multilevel inverter topology can be a good solution to feed microgrid from renewable energy sources. A six-level inverter was considered and controlled by using a PWHM technique, requiring only twelve switching states per period. Simulation studies have been performed on a six-level inverter based on the proposed structure and have been validated experimentally. The obtained simulation and experimental results have shown a $15 \%$ voltage THD rate, zeroed successive harmonics from $2^{\text {th }}$ to $10^{t h}$ orders. The first non-canceled harmonic is $11^{\text {th }}$ order with $9 \%$ of the fundamental magnitude. The proposed configuration gives a compact and low cost system with both minimum number of switches and less number of switching states with a simplified inverter control scheme. The efficiency, performance and compliance with IEEE519-1992 and IEC61000-3-12 standards have been validated. The low-frequency switching reduces the inverter power losses leading to a better efficiency of the proposed topology. Comparisons of the proposed topology with conventional topologies reveals that the proposed topology significantly reduces the number of power switches and associated gate driver circuits. Analytical comparisons on the basis of losses indicate that the proposed topology is highly competitive. On the horizon, the detailed real and reactive power control of the proposed inverter will be considered.

\section{REFERENCES}

[1] M. R. Islam, Y. Guo, and J. Zhu, "A High-Frequency Link Multilevel Cascaded Medium-Voltage Converter for Direct Grid Integration of Renewable Energy Systems," IEEE Trans. Power Electron., vol. 29, no. 8, pp. 4167-4182, Aug. 2014.

[2] M. Manojkumar, K. Porkumaran, and C. Kathirvel, "Power electronics interface for hybrid renewable energy system - A survey," in Proc. Int. Conf. Green Computing Communication and Electrical Engineering, Coimbatore, India, pp. 1-9, Mar. 2014.

[3] T. Adefarati, and R. C. Bansal, "Integration of renewable distributed generators into the distribution system: a review," IET Renew. Power Gener, vol. 10, no. 7, pp. 873-884, Jul. 2016.

[4] S. Dasgupta, S. N. Mohan, S. K. Sahoo, and S. K. Panda, "Application of Four-Switch-Based Three-Phase Grid-Connected Inverter to Connect Renewable Energy Source to a Generalized Unbalanced Microgrid System," IEEE Trans. Ind. Electron., vol. 60, no. 3, pp. 1204-1215, Mar. 2013.

[5] E. Solas, G. Abad, J. A. Barrena, S. Aurtenetxea, A. Cárcar and L. Zając, "Modular Multilevel Converter With Different Submodule Concepts-Part I: Capacitor Voltage Balancing Method," IEEE Trans. Ind. Electron., vol. 60, no. 10, pp. 4525-4535, Oct. 2013.

[6] X. Shi, B. Liu, Z. Wang, Y. Li, L. M. Tolbert, and F. Wang, "Modeling, Control Design, and Analysis of a Startup Scheme for Modular Multilevel Converters," IEEE Trans. Ind. Electron., vol. 62, no. 11, pp. 7009-7024, Nov. 2015

[7] S. Debnath, and M. Saeedifard, "A New Hybrid Modular Multilevel Converter for Grid Connection of Large Wind Turbines," IEEE Trans. Sustain. Energy, vol. 4, no. 4, pp. 1051-1064, Oct. 2013.
[8] R. Li, J. E. Fletcher, L. Xu, D. Holliday, and B. W. Williams, "A Hybrid Modular Multilevel Converter With Novel Three-Level Cells for DC Fault Blocking Capability," IEEE Trans. Power Del., vol. 30, no. 4, pp. 2017-2026, Aug. 2015.

[9] M. R. Islam, Y. Guo, and J. G. Zhu, "Performance and cost comparison of NPC, FC and SCHB multilevel converter topologies for high-voltage applications," in Proc. Int. Conf. Electrical Machines and Systems, Beijing, China, pp. 1-6, Aug. 2011.

[10] F. Deng, and Z. Chen, "A Control Method for Voltage Balancing in Modular Multilevel Converters," IEEE Trans. Power Electron., vol. 29, no. 1, pp. 66-76, Jan. 2014.

[11] X. She, A. Q. Huang, T. Zhao, and G. Wang, "Coupling Effect Reduction of a Voltage-Balancing Controller in Single-Phase Cascaded Multilevel Converters," IEEE Trans. Power Electron., vol. 27, no. 8, pp. 3530-3543, Aug. 2012.

[12] J. Rodriguez, Jih-Sheng Lai, and Fang Zheng Peng, "Multilevel inverters: a survey of topologies, controls, and applications," IEEE Trans. Ind. Electron., vol. 49, no. 4, pp. 724-738, Aug 2002.

[13] H. Abu-Rub, J. Holtz, J. Rodriguez, and G. Baoming, "Medium-Voltage Multilevel Converters-State of the Art, Challenges, and Requirements in Industrial Applications," IEEE Trans. Ind. Electron., vol. 57, no. 8, pp. 2581-2596, Aug. 2010.

[14] M. Malinowski, K. Gopakumar, J. Rodriguez, and M. A. Perez, "A Survey on Cascaded Multilevel Inverters," IEEE Trans. Ind. Electron., vol. 57 , no. 7, pp. 2197-2206, Jul. 2010

[15] N. Yousefpoor, S. H. Fathi, N. Farokhnia and, H. A. Abyaneh, "THD Minimization Applied Directly on the Line-to-Line Voltage of Multilevel Inverters," IEEE Trans. Ind. Electron., vol. 59, no. 1, pp. 373-380, Jan. 2012.

[16] Y. Liu, H. Hong, and A. Q. Huang, "Real-Time Algorithm for Minimizing THD in Multilevel Inverters With Unequal or Varying Voltage Steps Under Staircase Modulation," IEEE Trans. Ind. Electron., vol. 56, no. 6, pp. 2249-2258, Jun. 2009.

[17] I. Ahmed, and V. B. Borghate, "Simplified space vector modulation technique for seven-level cascaded H-bridge inverter," IET Power Electron., vol. 7, no. 3, pp. 604-613, Mar. 2014.

[18] K. A. Tehrani, I. Rasoanarivo, and F. M. Sargos, "Power losses calculation in two different multilevel inverter models (2DM2)," Elsevier, Electric Power Systems Research, vol. 81, no. 2, pp. 297-307, Feb. 2011.

[19] N. Mittal, B. Singh, S. P. Singh, R. Dixit, and D. Kumar, "Multilevel inverters: A literature survey on topologies and control strategies," in Proc. Int. Conf. Power Control and Embedded Systems, Allahabad, India, pp. 1-11, Dec. 2012.

[20] J. Rodriguez, S. Bernet, P. K. Steimer, and I. E. Lizama, "A Survey on Neutral-Point-Clamped Inverters," IEEE Trans. Ind. Electron., vol. 57, no. 7, pp. 2219-2230, Jul. 2010.

[21] F. Wu, B. Li and J. Duan, "Calculation of switching loss and current total harmonic distortion of cascaded multilevel grid-connected inverter and Europe efficiency enhancement considering variation of DC source power," IET Power Electron., vol. 9, no. 2, pp. 336-343, Feb. 2016.

[22] A. K. Rathore, J. Holtz, and T. Boller, "Generalized Optimal Pulsewidth Modulation of Multilevel Inverters for Low-Switching-Frequency Control of Medium-Voltage High-Power Industrial AC Drives," IEEE Trans. Ind. Electron., vol. 60, no. 10, pp. 4215-4224, Oct. 2013.

[23] S-A. Amamra, K. Meghriche, E. Monacelli, and A. Cherifi, "On the use of Pulse Height Modulation for harmonic cancellation in a six-level inverter topology", International Review of Modeling and Simulations, vol. 6, no. 3, pp. 676-683, Jun. 2013.

[24] IEEE, "Recommended Practices and Requirements for Harmonic Control in Electrical Power Systems," IEEE Std 519-1992 , pp.1-112, Apr. 1993.

[25] IEC, "Limits for Harmonics Current Produced by Equipment connected to Public Low Voltage Systems," IEC Std 61000-3-12, pp. 1-13, Nov. 2004.

[26] J. Ebrahimi, E. Babaei, and G. B. Gharehpetian, "A New Multilevel Converter Topology With Reduced Number of Power Electronic Components," IEEE Trans. Ind. Electron., vol. 59, no. 2, pp. 655-667, Feb. 2012.

[27] R. Teodorescu, F. Blaabjerg, J. K. Pedersen, E. Cengelci, and P. N. Enjeti, "Multilevel inverter by cascading industrial VSI," IEEE Trans. Ind. Electron., vol. 49, no. 4, pp. 832-838, Aug 2002.

[28] K. K. Gupta, and S. Jain, "A Novel Multilevel Inverter Based on Switched DC Sources," IEEE Trans. Ind. Electron., vol. 61, no. 7, pp. 3269-3278, Jul. 2014. 


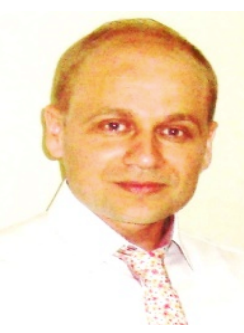

Sid-Ali Amamra was born in Ténès, Algeria. He received the $\mathrm{PhD}$ degree in electrical engineering in 2013 from University of Versailles Saint-Quentinen-Yvelines, France. He is Researcher at the Department of Electrical Engineering of Hautes Etudes d'Ingénieur (HEI) school. He is a member of Laboratory of Electrical Engineering (L2EP), Lille. He is currently working on advanced energy management systems for electrical networks and power systems.

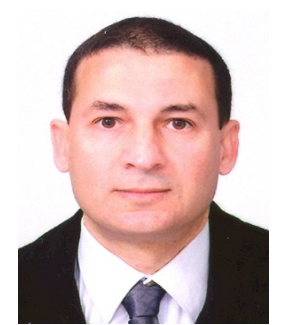

Kamal Meghriche was born in El-Milia, Algeria. $\mathrm{He}$ received his "engineer of State" and MSc. degrees in electrical engineering and applied electronics in 1987 and 1991 respectively from the National Institute of Electricity and Electronics, Boumerdes, Algeria. In 2002, he joined the Versailles Laboratory of Robotics (LRV), University of Versailles SaintQuentin-en-Yvelines (France) where he received his "Doctorat" (equiv. to $\mathrm{PhD}$ ) in Robotics in 2006. Currently, he is member of the Versailles Laboratory of Systems Engineering (LISV), associate professor at Mantes-en-Yvelines Institute of Technology and head of the Mechatronics Department of the Yvelines Institute of Science and Technology (ISTY). His current research interests are mainly focused on processing electrical power in order to match the power source to the load requirements, aiming electromobility applications.

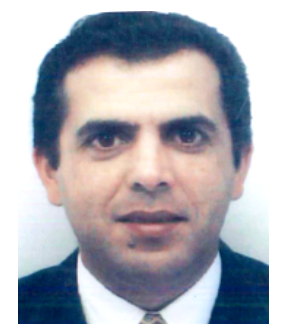

Abderrezzak Cherifi was born in Tlemcen, Algeria, in 1964. He received the Engineer degree in Elecrical Engineering (Electrotechnique) from the University of Oran, Algeria, in 1988. He received the M.Sc. degree (DEA) from Paul Sabatier University, Toulouse, France, in 1990, and the Ph.D. degree in electrical engineering from the University of Montpellier, France, in 1993. From 1993 to 2001, he was with the "Ecole d'Ingénieurs de Cherbourg", France as an Associate Professor of electrical engineering. $\mathrm{He}$ was also a member of the "Laboratoire des Sciences Appliquées de Cherbourg", France. In 2001 he joined the University of Versailles Saint-Quentin-en-Yvelines, France, where he is currently a Professor of Electrical Engineering. His research interests are in the field of Electrical Engineering. They include Systems modeling, design and control of dc-ac inverters, ac electric machines and non destructive space charge measurement in dielectrics.

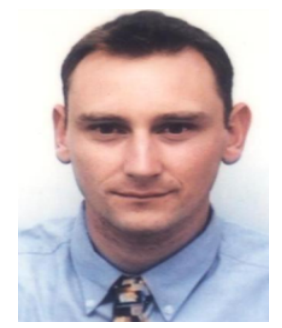

Bruno Francois (M'96-SM'06) was born in SaintAmand-les-Eaux, France. He received the $\mathrm{PhD}$ degree in electrical engineering in 1996 from the University of Science and Technology of Lille (USTL), France. He is full Professor at the Department of Electrical Engineering of Ecole Centrale de Lille. He is a member of Laboratory of Electrical Engineering (L2EP), Lille. He is currently working on advanced energy management systems for electrical networks and power systems. 